\title{
Study on breast feeding and complementary feeding practices in rural mothers, Tamilnadu, India
}

\author{
Sivagamasundari $V^{1}$, Appandraj $S^{2}$, Ramanath A.K ${ }^{3}$ \\ ${ }^{1}$ Dr. Sivagamasundari Venugopal, Assistant Professor, Department of Paediatrics, ${ }^{2}$ Dr. Appandraj Srivijayan, Professor, \\ Department of Internal Medicine, ${ }^{3}$ Dr. Andy Karayalar Ramanath. Professor, Department of Paediatrics, all authors are \\ affiliated with Karpagavinayaga Institute of Medical Sciences, Chinakolambakkam, Palayanoor post, Madhuranthagam \\ Taluk, Kancheepuram District, Tamilnadu, India.
}

Corresponding Author: Dr. Sivagamasundari Venugopal, Assistant Professor, Department of Paediatrics, Karpagavinayaga Institute of Medical Sciences, Chinakolambakkam, Palayanoor Post, Madhuranthagam Taluk, Kancheepuram District-Tamilnadu. E-mail: gamapps@yahoo.com.

\begin{abstract}
Introduction: Breast feeding of infants and young child is the natural and effective method which plays a major role in reducing the mortality of infants and under five children. There is significant reduction in the morbidities in the above age due to breast feeding. Inadequate knowledge and poor practices of breast feeding hinders the successful establishment of breast feeding. Objective: To determine the breast feeding and complementary feeding practices of mothers with children of age below 3 years from rural area who visited the outpatient department of paediatrics of karpagavinayaga institute of medical sciences, Kancheepuram, Tamilnadu. Materials and Methods: This was across sectional study done in hospital from 2017 September to 2018 January for a total duration of five months with structured questionnaire. Results: Exclusive breast feeding was given to $68.7 \%(n=76)$ of children. About $69.5 \%$ of the mothers had initiated the breast feeding within one hour of delivery. About $89.6 \%$ had given colostrum. Prelacteal feeds were given in $10.4 \%$. Only $32.2 \%$ of mothers fed their babies on demand. Complementary feeding was started after six months by $80.9 \%$ mothers. Complementary feeding was started with homemade food by $49.6 \%$ of mothers. Conclusion: This study emphasis on education of mothers during their antenatal care, postnatal care and follow up care by obstetricians, paediatricians, residents and staff nurses regarding the importance of breast feeding and their advantages for better outcome in terms of reducing the morbidities and mortality in children below five years.
\end{abstract}

Keywords: Exclusive breast feeding Prelacteals, Demand feed, Complementary feeding.

\section{Introduction}

Breastfeeding is an important and effective method of infant feeding that causes significant reduction in the mortality and morbidity in children under 1 year of age and under 5 years [1].The acute morbid conditions like lower respiratory tract illness, necrotizing enterocolitis, diarrhoea, otitis media and long-term morbid conditions like diabetes, obesity, and hypertension are greatly reduced by exclusive breast feeding for first six months, continued feeding till 2 years or more and timely introduction of complementary feed [2].

World Health Organization and UNICEF recommend that infants should be fed with breast milk exclusively for first six months of life and then complementary

Manuscript received: $4^{\text {th }}$ February 2019

Reviewed: $14^{\text {th }}$ February 2019

Author Corrected: $20^{\text {th }}$ February 2019

Accepted for Publication: $24^{\text {th }}$ February 2019 feeding of nutritious and safe nature should be introduced along with continued breastfeeding for two years and beyond [3]. In child health, positive approach by family members particularly parents because of increasing nuclear family towards infant feeding is necessary in bringing down the growing burden of malnutrition which is a considerable problem in developing countries among under5 children [4].Breast feeding in addition to natural, easily available and cost effective it is rich in all nutrients and immunoglobulin needed by newborn baby and young children.

According to 2015-2016NFHS -4 survey IMR (Infant mortality rate) and under 5 mortality rate are $41 \%$ and $50 \%$ respectively [5]. This can be reduced effectively brought down by creating the awareness about the importance of breast feeding and good breastfeeding 


\section{Original Research Article}

practices. Intelligence and academic performance of the breast fed infants and young child are in the higher level compared to cow's milk and formula fed infants [6]. In one trial the authors have shown that by initiating the breast feeding earlier within one hour of birth can reduce the neonatal mortality rate (NMR) by $22 \%$ [7]. Successful breast feeding practices will lead to the achievement of millennium development goals (MDGs) [8].

Studies in developing countries like India revealed that there is inadequacy in practices of breastfeeding and complementary feeding among mothers due to inadequate knowledge, woman employment and increasing urbanization.

Practices regarding exclusive breastfeeding, time of initiation of breastfeed, colostrum feeding, demand feeding, pre-lacteal feeds, time of initiation and type of complementary feed are limited between mothers.

This study discloses the practices of breastfeeding and complementary feeding between the mothers of our rural area.

\section{Materials and Methods}

Study design: This was a cross sectional study done in our institution.

Study setting: The study was done in the outpatient department of paediatrics of Karpaga Vinayaga Institute of Medical Sciences, Kancheepuram, Tamilnadu.

Study duration: The study was conducted for five months from 2017 September to January 2018.

Study population: Mothers with children of age below 3 years from rural area who visited the outpatient department of paediatrics of Karpagavinayaga Institute of Medical Sciences, Kancheepuram, Tamilnadu for immunisation or any other minor illness were recruited in this study.

Sample size and sampling: Sample size of 115 was estimated with the formula $4 \mathrm{pq} / \mathrm{L} 2$. In this formula $\mathrm{p}$ stands for prevalence, $q$ was derived from 1-p and $L$ stands for absolute precision.

Inclusion criteria: Those mothers with children of age below 3 years from rural area who visited the outpatient department of paediatrics our hospital were included in the study.

Exclusion criteria: The mothers with children of age below 3 years from urban areas and the mothers with children above 3 years of age.

Study instruments: pretested structured questionnaire

Data collection: The mothers were interviewed by authors with structured questionnaire that is pretested. The structured questionnaire part -I consisted of socio demographic details such as children's age, gender and order of birth, mother's age, occupation and educational status. The structured questionnaire part-II consisted of variables like time of initiation of breastfeeding, colostrum feeding, practice of prelacteal feed, demand feeding practices, burping, exclusive breastfeeding and time of initiation and type of complementary feeding practices.

Data analysis: All the data were entered in excel sheet and analysis was done using SPSS software version 20. Results were drawn and displayed in terms of percentages and frequencies.

Ethical issues: The study was done after obtaining ethical clearance from the institutional ethical committee. The mothers were explained about the nature of the study and their consent was obtained in written.

\section{Results}

115 mothers with children below three years were recruited into this study. $89.5 \%$ of mothers were between $20-30$ years of age. Most of the mothers were homemakers $80.9 \%$ in this study. only $19.1 \%$ was employed. $49.6 \%$ of the mothers had secondary level educational qualification. $97.3 \%$ of the deliveries had occurred in hospitals. $47.8 \%$ of mothers delivered their babies via labour natural. $49.5 \%$ of mothers had children below or equal to 12 months.

Based on the sex of the child $42.6 \%$ were girls and $57.4 \%$ were boys. The sociodemographic details of both the mother and children were depicted in Table -1 .

In this study $69.5 \%(n=80)$ of the mothers had initiated the breast feeding within one hour of delivery and $20.9 \%$ ( $n=24)$ had initiated their feed in 1-6 hours and only 9.6\% $(n=11)$ after 6 hours. 89.6\% $(n=103)$ had given the colostrum and $10.4 \%(n=12)$ discarded the colostrum. Prelacteal feeds such as sugar water, cow's milk, donkey's milk and honey were 


\section{Original Research Article}

given in $10.4 \%$. Exclusive breast feeding for six months was given to $68.7 \%(\mathrm{n}=76)$ of children. In $31.3 \%$ ( $\mathrm{n}=36$ ) exclusive breast feeding was not given. Only 32.2\% $(n=37)$ of mothers fed their babies on demand.47.8\% $(n=55 \%)$ mothers followed scheduled feed and remaining $20 \%(n=23)$ practised both.

Burping was done by $93 \%(n=107)$ of mothers. Most of mothers $75.7 \%(n=87)$ offered feed from both the breast during each feed and only $24.3 \%(n=28)$ fed their babies from one breast per feed. Complementary feeding was started after six months by $80.9 \%(n=93)$ and before 6 months in $19.1 \% \quad(n=22)$.

Complementary feeding was started with homemade food by $49.6 \%(n=57)$ and by formula food by $43.4 \%(n=50)$ and both by $7 \%(n=8)$. Breast feeding and complementary feeding practices are shown in Table 2 and Table 3.

Table-1: Socio demographic profile.

\begin{tabular}{|c|c|c|}
\hline Variable & Percentage $=N * 100 / N$ & Frequency $(\mathrm{N}=)$ \\
\hline \multicolumn{3}{|l|}{ Mothers' age } \\
\hline $20-30$ years & 89.5 & 103 \\
\hline $31-40$ years & 10.5 & 12 \\
\hline \multicolumn{3}{|l|}{ Occupational status } \\
\hline Home maker & 80.9 & 93 \\
\hline Employed & 19.1 & 22 \\
\hline \multicolumn{3}{|c|}{ Educational qualification } \\
\hline Illiterate & 4.3 & 5 \\
\hline Primary & 2.6 & 3 \\
\hline Secondary & 49.6 & 57 \\
\hline Higher secondary & 20.9 & 24 \\
\hline Graduate and above & 22.6 & 26 \\
\hline \multicolumn{3}{|l|}{ Age of the children } \\
\hline $0-12$ months & 49.5 & 57 \\
\hline $12-24$ months & 33.1 & 38 \\
\hline $24-36$ months & 17.4 & 20 \\
\hline \multicolumn{3}{|c|}{ Birth order of children } \\
\hline $1^{\text {st }}$ & 49.6 & 57 \\
\hline $2^{\text {nd }}$ & 41.7 & 48 \\
\hline $3^{\text {rd }}$ & 8.7 & 10 \\
\hline \multicolumn{3}{|l|}{ Gender of children } \\
\hline Boy & 57.4 & 66 \\
\hline Girl & 42.6 & 49 \\
\hline \multicolumn{3}{|l|}{ Place of delivery } \\
\hline Hospital & 97.3 & 112 \\
\hline Home & 2.7 & 3 \\
\hline \multicolumn{3}{|l|}{ Mode of delivery } \\
\hline Labour natural & 47.8 & 55 \\
\hline Cesarean section & 52.2 & 60 \\
\hline
\end{tabular}




\section{Original Research Article}

Table-2: Breastfeeding Practices.

\begin{tabular}{|c|c|c|}
\hline Practices & Number(n=) & Percentage (\%) \\
\hline \multicolumn{3}{|c|}{ Initiation of breast feeding after birth } \\
\hline Within 1 hour & 80 & 69.5 \\
\hline $1-6$ hours & 24 & 20.9 \\
\hline 6-72 hours & 11 & 9.6 \\
\hline \multicolumn{3}{|l|}{ Demand feed } \\
\hline Demand feed & 37 & 32.2 \\
\hline Scheduled feed & 55 & 47.8 \\
\hline Both & 23 & 20 \\
\hline \multicolumn{3}{|l|}{ Colostrum } \\
\hline Given & 103 & 89.6 \\
\hline Not given & 12 & 10.4 \\
\hline \multicolumn{3}{|l|}{ Exclusive breast feeding } \\
\hline Given & 76 & 68.7 \\
\hline Not given & 36 & 31.3 \\
\hline \multicolumn{3}{|l|}{ Burping } \\
\hline Done by & 107 & 93 \\
\hline \multicolumn{3}{|l|}{ Feeding from one breast at one time } \\
\hline Feeding from one breast at a time & 28 & 24.3 \\
\hline Both breast at a time & 87 & 75.7 \\
\hline \multicolumn{3}{|l|}{ Prelacteal feed } \\
\hline Not given & 103 & 89.6 \\
\hline Prelacteal feed given & 12 & 10.4 \\
\hline a. Sugar water & 7 & 6.08 \\
\hline b. Cow's milk & 1 & 0.87 \\
\hline c. Donkey’s milk & 3 & 2.60 \\
\hline d. Honey & 1 & 0.87 \\
\hline
\end{tabular}

Table-3: Complementary Feeding Practices.

\begin{tabular}{|l|c|c|}
\hline Complementaryfeedingpractices & Number(n=) & Percentage (\%) \\
\hline Complementaryfeedingstarted & 93 & 80.9 \\
\hline After 6 months & 22 & 19.1 \\
\hline Before 6 months & 57 & 49.6 \\
\hline Type of complementary food introduced & 50 & 43.4 \\
\hline Home made & 8 & 7 \\
\hline Formula food & & \\
\hline Both & & \\
\hline
\end{tabular}

\section{Discussion}

The World Health Organisation recommends exclusive breast feeding for first 6 months which will reduce the infant mortality and under 5 mortality and later reduces childhood morbidity [3]. In this present study $68.7 \%$ of mothers had exclusively breastfed their children for 6 months. In study by Shaili V et al [9] only 5.13\% of mothers had given their infants exclusive breast feed for first 6 months. According to NFHS-4 survey [5], only $54.9 \%$ children under 6 months of age were exclusively breast fed. In study by Dandekar RH et al[10] 79.2\% of mothers had exclusively breast fed their children. Most of the mothers initiated weaning at an earlier month due to fear of in sufficient milk for the growth of their children. 


\section{Original Research Article}

The World Health Organisation recommends that the breast feeding should be initiated within 1 hour of the birth of new born [3]. Initiation of breast feeding within 1 hour of birth provides protection against infection like sepsis, pneumonia, diarrhoea and hypothermia, thereby reduces the neonatal mortality [11]. It was found that there was doubling the risk of neonatal mortality when breast feeding initiation was delayed beyond one hour of birth [12].

In this present study $69.5 \%$ of mother had initiated breast feeding within one hour of delivery. In study by Sharif M et al [13] only $35.9 \%$ of the mothers had given their children breast feed within one hour of birth of delivery. In study by Ekubay $\mathrm{M}$ et al [11] only $58.3 \%$ of mothers had given their newborn breast feed within the first one hour of delivery. According to NFHS-4 survey [5] only $41.6 \%$ of the children had been initiated breast feeding within one hour of birth.

Colostrum which is called the first milk is the perfect food to the newly delivered babies [3]. It is rich in immunoglobulins and other protective factors and should not be discarded. In this study colostrum was given to $89.6 \%$ of newborn babies and the mothers in this study were aware of the fact that colostrum is immunogenic. In study by Dandekar RH et al [10] $77.6 \%$ of the mothers fed their newborn with colostrum.

Giving prelacteal feed to the newborn leads to delay in the let-down reflex of milk and lactation failure. Prelacteal feed also increases the diarrhoeal episodes and sepsis and thereby increases the infant mortality rate [14]. In this present study only $10.4 \%$ of mother had given their newborn prelacteal feed which is very low compared to other studies.

This shows that mothers in our study were well aware of the fact that prelacteal feed will be harmful to their newborn. In study by Shaili V et al [9] $66.03 \%$ of the babies were given prelacteal feed and in study by Mandal et al [15] 71.7\% were given prelacteal feed which is very high compared to our study.

In this present study demand feeding was practised only by $32.2 \%$ of mothers. The WHO recommends that the babies should be fed on demand feed as one of the ten steps to establish successful breastfeeding [3]. In our study the knowledge about the demand feeding is lacking hence the mothers should be educated about demand feeding importance to improve adequate milk supply. According to a study the children those who fed on demand had good cognitive and academic outcomes than that of the children who were fed on scheduled feed [16]. In Shaili V et al [9] study $89 \%$ of the mothers have fed their babies on demand which is very high whereas in study by Harnagle $\mathrm{R}$ et al [4] $32.7 \%$ of babies were fed on demand which is similar to our study. In this present study complementary feeding was started after 6 months in $80.9 \%$ children. In Maiti A et al [17] study only $15.8 \%$ of the mothers had started complementary feed after 6 months.

According to WHO guidelines complementary feed should be started after 6 months along with continued breast feeding for two years in order to prevent the children to fall in malnutrition ${ }^{2}$. In this present study homemade foods were introduced as the complementary feed in $49.6 \%$ of children. In Maiti A et al [17] study only $23.42 \%$ of the children had introduced homemade food as weaning food.

Commercially prepared weaning foods may be beyond the reach of poor people. It is advisable to prepare weaning food by culturally, socially, economically acceptable and easily available local food products.

\section{Conclusion}

In developing countries where the majority of people in the lower socioeconomic group, breast feeding is the natural, economical and cost effective method of feeding for infant and young.

This study emphasis on education of mothers during their antenatal care, postnatal care and follow up care by obstetricians, paediatricians, residents and staff nurses regarding the importance of breast feeding and their advantages for better outcome in terms of reducing the morbidities and mortality in children below five years.

\section{What This Study Adds?}

Importance and the need for breast feeding should be provided to the close family members to increase their support for breast feeding.

Contributors: SV: developed the concept and designed the study, wrote the manuscript, AS: did data analysis, AKR: helped in review of the literature. All the authors involved in collection of data and approved the final manuscript.

Funding: Nil, Conflict of interest: None initiated, Perission from IRB: Yes

Ethical approval: The study was approved by Institutional ethical committee 


\section{References}

1. Sankar MJ, Sinha B, Chowdhury R, et al. Optimal breastfeeding practices and infant and child mortality: a systematic review and meta-analysis. Acta Paediatr. 2015 Dec; 104 (467): 3-13. doi: 10. 1111/ apa. 13147.

2.James DC, Lessen R; American Dietetic Association. Position of the American Dietetic Association: promoting and supporting breastfeeding. J Am Diet Assoc. 2009 Nov;109(11):1926-42.

3. WHO and UNICEF. Global strategy for infant and young child feeding. World Health Organization, Geneva, 2003. Available at www.who.int/nutrition/ publications /9241562218/en/

4. Harnagle R, Chawla P S. A study of knowledge, attitude and practices of lactating mothers on breast feeding, weaning immunization and dietary practices at Jabalpur cantonment, India. Int. J. Microbiol. App. Sci. 2013; 2 (11): 393-403.

5. National Family Health Survey (NFHS-4). Factsheets 2015 - 2016. India: International Institute for Population Sciences. Available from URL: http://www.nfhsindia. org. Accessed on 9June 2017.

6. Som B, Tripura K. A cross-sectional study regarding knowledge about breastfeeding among primi pregnant mothers attending for antenatal check up in a medical college. Tripura. J. Evolution Med. Dent. Sci.2016;5 (81): 6061-3.

7. Edmond KM, Zandoh C, Quigley MA, et al. Delayed breastfeeding initiation increases risk of neonatal mortality. Pediatrics. 2006 Mar;117(3):e380-6. DOI:10. 1542/ peds.2005-1496

8. Ministry of statistics and programme implementation. NewDelhi: Central statistics organization. Millennium Development Goals. Final country report of India Government of India. Available at URL:http:// www. mospi. gov.in. Accessed on 19 February 2019.
9. Shaili V, Parul S et al. A community based study on breastfeeding practices in a rural area of Uttarakhand. Nat J Comm Med. 2012;3(2):283-7.

10. Dandekar RH, Shafee M, Kumar R. Breast feeding and weaning practices among literate mothers. The Health Agenda. 2014 ;2(1):15-25.

11. Ekubay M, Berhe A, Yisma E. Initiation of breastfeeding within one hour of birth among mothers with infants younger than or equal to 6 months of age attending public health institutions in Addis Ababa, Ethiopia. Int Breastfeed J. 2018 Jan 23;13:4. doi: 10. 1186/s13006-018-0146-0. eCollection 2018.

12. Khan J, Vesel L, Bahl R, et al. Timing of breastfeeding initiation and exclusivity of breastfeeding during the first month of life: effects on neonatal mortality and morbidity--a systematic review and metaanalysis. Matern Child Health J. 2015 Mar;19(3):46879. doi: 10.1007/s10995-014-1526-8.

13. Sharif M, Saxena A, Nair S, Sharma A, Jain P. Knowledge, attitude and practices of nursing mothers toward breastfeeding in a tertiary care center in Navi Mumbai. Indian J Child Health. 2017; 4(2):243-7.

14. Akuse RM, Obinya EA. Why healthcare workers give prelacteal feeds. Eur J Clin Nutr. 2002 Aug;56 (8): 729-34. DOI:10.1038/sj.ejcn.1601385

15. Mandal PK, Sardar JC, Chatterjee C, Lahiri SK, Ghosh PK.Astudy on breast feeding practices among infants in a rural area of West Bengal. Indian J Prevand Soc Med. 2007; 38(1\& 2):28-31.

16. Lacovou M, Sevilla A. Infant feeding: the effects of scheduled vs. on-demand feeding on mothers' wellbeing and children's cognitive development. Eur J Public Health. 2013 Feb;23(1):13-9. doi: 10.1093/eurpub/ cks 012. Epub 2012 Mar 14.

17. Maiti A, Sarangi L. Assessment on breastfeeding and weaning practices in Odisha, India. Am J Pub Health Res. 2015;3(4A):49-52.

\section{How to cite this article?}

Sivagamasundari V, Appandraj S, Ramanath A.K. Study on breast feeding and complementary feeding practices in rural mothers, Tamilnadu, India. Int J Pediatr Res. 2019;6(02):97-102.doi:10.17511/ijpr.2019.i02.10 